Ärztliche Erfahrung beschränkt sich nicht auf medizinisches Fachwissen. Sie entsteht auch aus den mehr oder minder alltäglichen, heiter, ärgerlich oder nachdenklich stimmenden Erlebnissen mit Patienten, Kollegen und Mitarbeitern. Senden Sie uns Ihre Geschichte an: Brigitte.Moreano@springer.com. Für jeden veröffentlichten Text erhalten Sie bis zu 100 Euro.

\title{
Ein giftiges Argument
}

- Vor einigen Jahren kam ein Mann, nennen wir ihn Herr Müller, im Rahmen der alle drei Jahre fälligen arbeitsmedizinischen Vorsorgeuntersuchung zu mir. Als erstes fragte mich Herr Müller, ob ich ihn auch beim letzten Mal vor drei Jahren untersucht hätte. Das konnte ich mit einem Blick in die Karteikarte bestätigen. Daraufhin meinte Herr Müller: „Wenn ich das gewusst hätte, hätte ich Ihnen einen Blumenstrauß mitgebracht." Erstaunt fragte ich nach, warum dieses.

Da erzählte Herr Müller: „Frau Doktor, vor drei Jahren haben Sie mich im Rahmen der Untersuchung gefragt, ob ich rauche.
Meine Bestätigung zum Rauchen haben Sie mit einer kurzen, aber nicht sehr erfreuten Reaktion aufgenommen. Bei der Frage, ob ich regelmäßig Medikamente nehme, habe ich Ihnen gesagt, dass ich Medikamente grundsätzlich ablehne, weil sie ja Gift seien.

Am Ende der Untersuchung vor drei Jahren, als ich schon in der Tür stand, haben Sie, Frau Doktor, dann noch gesagt, dass Sie eines nicht verstünden, nämlich dass ich Medikamente als giftig so strikt ablehne, aber dass ich mir mit dem Rauchen ständig freiwillig das starke Gift Nikotin zuführe. Diese letzte Bemerkung im Hinausgehen vor drei Jahren hatte mich ins Grü- beln gebracht und fast sofort habe ich aufgehört zu rauchen."

Herr Müller bedankte sich überschwänglich, dass ich ihn zum Rauchverzicht motiviert hatte und bedauerte, dass er mir keine Blumen mitgebracht hatte.

Dass ich den Blumenstrauß nicht bekam, konnte ich gut verkraften, seinen guten Willen hatte Herr Müller ja bewiesen. Und dass es mir mit einem Satz gelungen ist, jemandem zu bewegen, mit dem Rauchen aufzuhören, war ein schönes Erfolgserlebnis für mich.

Dr. Med. ANKe KLinKeR, Wedel -

\section{Manchmal hilft nur Zauberei}

- Meine Patientin war heute Morgen wirklich genervt. „Ich habe seit Monaten eine Erkältung nach der anderen!", klagte sie. Erst war es Schnupfen, dann kam eine Sinusitis, und nun saß sie schon wieder bei mir mit Halskratzen, Kopfweh und ersten Hustenattacken. Nach der Untersuchung stand sie schon fast an der Tür, als sie sich noch einmal umdrehte: "Nehmen Sie doch einfach den Fluch von mir!", sagte sie, ,ich habe es so satt!"

Ich überlegte nur kurz, ob diese junge Frau einen Scherz vertragen könnte, und dann ging ich mit bedeutungsvoller Miene zu

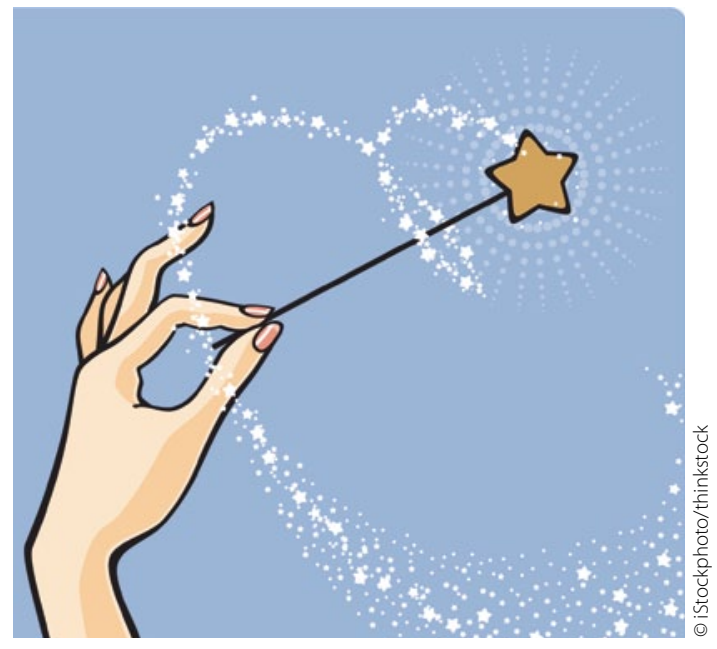

Wenn's hilft, ist auch gegen ein bisschen Simsalabim nichts einzuwenden. meinem Schreibtisch, öffnete eine Schublade und zog einen glitzernden Zauberstab heraus. Mit dem berührte ich die Patientin leicht an der Schulter und sagte so leise "Simsalabim!", dass man es garantiert vor der Sprechzimmertür nicht hören konnte (was hätte man sonst von mir gedacht?). Sie stutzte kurz, dann überzog sich ihr Gesicht mit einem strahlenden Lächeln. Kichernd ging sie hinaus, und ich dachte mir, dass schon ihre gute Laune ihr Befinden bessern wird. Meinen Zauberstab werde ich dennoch nur in Ausnahmefällen für Erwachsene benutzen.

Dr. med. Frauke Höllering, ARnSberg = 